\title{
Research progress on indoor environment of mushroom factory
}

\author{
Long Chen ${ }^{1,2 \dagger}$, Lei Qian ${ }^{1,2 \dagger}$, Xiao Zhang ${ }^{1,2}$, Jiazheng Li ${ }^{1,2}$, Zhijun Zhang ${ }^{1,2}$, Xiaoming Chen ${ }^{1,2^{*}}$ \\ (1. Tianjin Academy of Agricultural Sciences, Tianjin 300192, China; \\ 2. National Engineering and Technology Research Center for Preservation of Agricultural Products/Key Laboratory of Storage of \\ Agricultural Products, Ministry of Agriculture and Rural Affairs/Tianjin Key Laboratory of Postharvest Physiology and Storage of \\ Agricultural Products, Tianjin 300384, China)
}

\begin{abstract}
Mushroom factory is an emerging production mode that is relied on facility and equipment by creating a suitable, steady, and uniform growing environment to accommodate the demand of edible fungus at each stage of growth. Therefore, an optimal range of key environmental factors (temperature, humidity, light, and $\mathrm{CO}_{2}$ concentrations) in mushroom facilities is crucial to achieving satisfactory production rates. This research aimed to provide an overview of recent progress on indoor environmental studies of mushroom cultivation facilities from three perspectives, 1) the development of environmental monitoring and controlling systems; 2) the application of computer modelling in addressing indoor environmental issues; 3) the refinement of mushroom facility design, including structure and ventilation scheme. With the aid of cutting-edge technologies, accomplishments have been made in developing smart farming systems that facilitate real-time recording of environmental parameters and automatic regulation of equipment, which helps the establishment of growth models for specific mushroom species. Computational Fluid Dynamics (CFD) modelling has been adopted by researchers to investigate indoor airflow patterns and assess the distribution of critical environmental parameters. Studies have been conducted to modify the design of mushroom facilities to improve the performance in structural stability, ventilation efficiency, and internal environmental condition. However, some existing problems still need further investigations, such as the lack of design guidelines, energy-saving strategies, and Artificial Intelligent (AI) quality control. Therefore, this overview was expected to provide constructive insights for future studies in addition to references of previous studies.
\end{abstract}

Keywords: modern farming, mushroom factory, indoor environment control, computational fluid dynamics, remote sensing DOI: $10.25165 /$ j.ijabe.20221501.6872

Citation: Chen L, Qian L, Zhang X, Li J Z, Zhang Z J, Chen X M. Research progress on indoor environment of mushroom factory. Int J Agric \& Biol Eng, 2022; 15(1): 25-32.

\section{Introduction}

Global mushroom production is currently on a shift to a highly commercialized farming mode that is usually called "mushroom factory" ${ }^{\text {"1] }}$. Similar to a plant factory ${ }^{[2-4]}$, a mushroom factory provides desired conditions for edible fungus growing within a controlled-environment facility that is regulated and operated by sophisticated technologies ${ }^{[5]}$. Mushroom factory facilitates mushroom farming in high efficiency by offering a standardized and all-year-round production mode, minimizing the constraints of natural climate. As a representative of modern farming, the production rate of a mushroom factory can reach up to $150 \mathrm{~kg} / \mathrm{m}^{2}$ annually, topping all food crops ${ }^{[5]}$. The total yields of mushroom factories in China were 3.28 million $t$ in 2018, yet merely $8.6 \%$ of

Received date: 2021-07-05 Accepted date: 2021-12-24

Biographies: Long Chen, PhD, Assistant Researcher, research interest: indoor environment modelling of agricultural facility, Email: lchen6316@icloud.com; Lei Qian, PhD, Associate Researcher, research interest: edible fungi cultivation and post-harvest processing, Email: qianlei507@126.com; Xiao Zhang, MS, Research Associate, research interest: logistics of agricultural products, Email: zx_18510736131@163.com; Jiazheng Li, PhD, Researcher, research interest: post-harvest packaging of agricultural products, Email: lijzh163@163.com; Zhijun Zhang, Researcher, research interest: edible fungi cultivation and post-harvest processing, Email: tjzhangzj@sina.cn.

$\dagger$ These authors contributed equally to this work.

*Corresponding author: Xiaoming Chen, $\mathrm{PhD}$, Associate Researcher, research interest: natural product and food processing, Tianjin Academy of Agricultural Sciences, No. 82 Jinjing Road, Xiqing District, Tianjin 300192, China. Tel: +86-22-27950117, Email: chxm001@126.com. total national mushroom yields. The percentage was predicted to reach $20 \%-30 \%$ by $2030^{[5]}$.

Unlike conventional family mushroom sheds, mushroom farming in a controlled environment is a complex biosystem ${ }^{[6,7]}$. So far, more studies have been performed focusing on the nutritional perspective of mushroom cultivation, investigating sustainable substrate materials, novel chemical additives, mushroom morphology, life cycle assessment, and so on ${ }^{[8-12]}$. However, few studies have been conducted to address environmental issues related to mushroom cultivation. Critical environmental factors, including temperature, humidity, light, and gas concentrations $\left(\mathrm{CO}_{2}\right)$, have significant influences on fungus growth and development ${ }^{[6,7,13,14]}$. Therefore, a rule of thumb in modern mushroom farming is to guarantee individual environmental factors are maintained optimal at every single stage of growth to obtain the best production rate ${ }^{[13-17]}$.

Studies on the indoor environment of a mushroom factory can be classified into three major categories, 1) the development of devices that monitor environmental parameters and process environment-controlling; 2) application of computer modelling to simulate indoor airflow and analyze the distribution of key environmental factors; 3) improvement of facility design, including refinement of ventilation features and management of equipment. This review aimed to introduce research progress in recent years from the three perspectives. In addition to providing references for future research, discussions were presented with insights on the existing issues. 


\section{Indoor environment supervision and control}

One of the core concepts of modern mushroom farming is to maintain a desired and steady cultivation environment. A number of investigations have been performed to develop devices and algorithms that capture real-time environmental parameters and precisely regulate the ventilation system and the equipment, minimizing the unexpected fluctuation of environmental parameters.

\subsection{Remote sensing and data transmission}

Monitoring and collecting environmental data allow growers and researchers to figure out the optimal range of individual environmental factors for a certain species. Researchers developed a wirelessly remote monitoring and data transmission system for a king oyster mushroom (Pleurotus eryngii) factory ${ }^{[18,19]}$. They combined multi-sensor fusion technology together with GPRS (General Packet Radio Service) wireless communication and image transmission to capture real-time data of indoor environment (temperature, relative humidity, and $\mathrm{CO}_{2}$ concentration). Chen et al. $^{[20]}$ designed a remote monitoring system for the community-style growing environment of king oyster mushroom by integrating similar technologies to record all environmental factors including light intensity. Later, a study was conducted by Zhao and $\mathrm{Zhu}^{[21]}$ who designed a single-chip wireless monitoring platform to monitor environmental factors simultaneously in eight mushroom farms, aiming to construct an accurate remote sensing system by eliminating problems of wiring difficulties, high-cost, and unstable data transmission.

Lee et al. ${ }^{[22]}$ documented product quality of bottle-cultivated Enokitake (Flammulina velutipes), corresponding to the data of environmental parameters (temperature, humidity, and $\mathrm{CO}_{2}$ concentrations) that were collected by environmental sensors in a single cultivation cycle of fruiting (28 d). Additionally, an environmental monitoring system was developed for the cultivation room of Hypsizygus marmoreus by Zhang et al. ${ }^{[23]}$. Real-time data of $\mathrm{CO}_{2}$ concentration was monitored along with temperature and humidity. A suggested regulation strategy of the ventilation system was proposed based on the experimental data collected. All those studies above demonstrated the necessity of collecting practical environmental data during mushroom cultivation.

\subsection{Smart control}

Researchers applied modern industrial control systems (ICS) to optimize the environment control system in the mushroom factory with the aid of automation and computer technologies, as well as practical experiences from the greenhouse ${ }^{[15,24-26]}$.

Yoon et al. ${ }^{[27]}$ conducted an experiment for consecutive two months to find out the reasonable range of each environmental factor and the relationship with yields of a king oyster mushroom factory. Another group of Korean researchers ${ }^{[28]}$ developed a technology to manage the cultivation environment automatically by developing an algorithm based on empirical data. The same methodology was then adopted by Lee et al. to develop an optimal growth model designated for the cultivation of bottle-grown oyster mushrooms $^{[29,30]}$.

Kim et al. ${ }^{[31]}$ conducted a similar investigation on king oyster mushrooms to collect practical data of $\mathrm{CO}_{2}$ concentrations, and characterized the impact of $\mathrm{CO}_{2}$ on mushroom yields and quality. Later, Tian et al. ${ }^{[32,33]}$ developed a $\mathrm{CO}_{2}$ concentration prediction model using initial $\mathrm{CO}_{2}$ concentration and the relative growth time as the inputs. The model was built based on priorly recorded environmental data using Back Propagation (BP) Neural Network. Additionally, a fuzzy controller was proposed based on the model to regulate the ventilation system and equipment operation for a king oyster mushroom factory ${ }^{[32]}$.

\subsection{Information and communication technology (ICT)}

With the development of internet-based communication technology, such as the Internet of Things (IoT), more emerging techniques have been applied in agricultural production ${ }^{[26,34-36]}$. Furthermore, IoT is considered as another information and industrial wave after the invention of personal computers, the Internet, and mobile communication networks ${ }^{[37]}$. This technology allows faster and more stable data transmission at low costs without wiring problems ${ }^{[34,37,38]}$.

Marzuki and Ying engineered an android device to monitor the real-time data of all environmental factors (including light intensity) in a mushroom farm using an IoT interface called "ThingSpeak"[39]. This control system included three different modes with specific sets of optimal conditions, according to the stage of mushroom growing. Similarly, an IoT-based monitoring and control system was developed for Shiitake cultivation by a group of Malaysian researchers ${ }^{[40]}$, they integrated wireless sensor network (WSN) and mobile computing technology to improve production efficiency of local mushroom farms (Figure 1). With the control system, the Shiitake yield was increased by $192.6 \%$ compared to the conventional cultivation mode ${ }^{[38]}$.

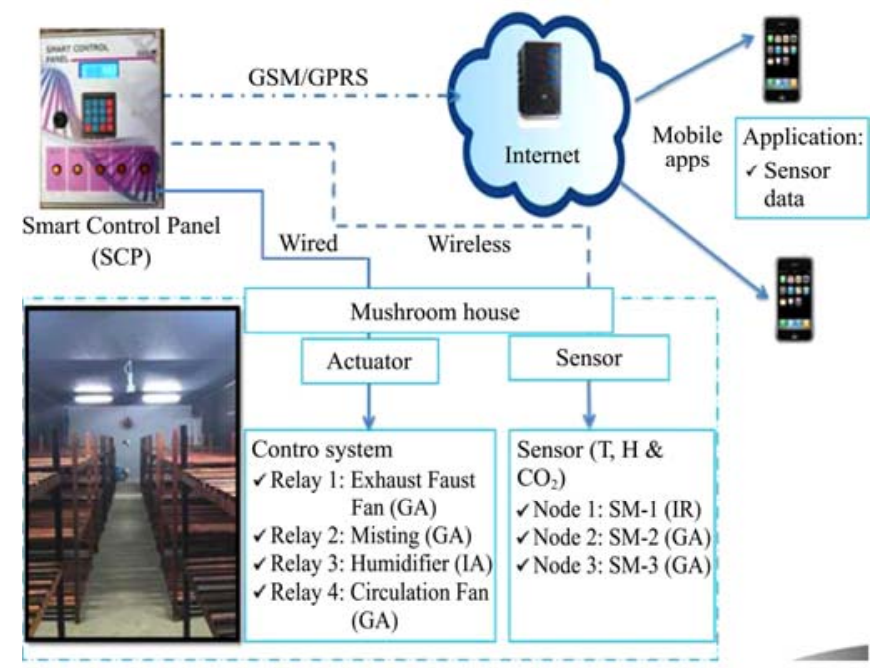

Note: $\mathrm{T}$ is the temperature; $\mathrm{H}$ is the Humidity; $\mathrm{CO}_{2}$ is the Carbon Dioxide; GA represents the growth area; IA represents the incubation area.

Figure 1 Schematic structure of the environmental monitor and control system of a mushroom factory using IoT $^{[38]}$

The work mentioned above was summarized in Table 1 . Accomplishments have been made by employing cutting-edge technologies to optimize environment monitoring and environment control system. The advancing technologies of remote sensors and wireless data transmission have enabled the evolution of environment monitoring and control devices/systems. Real-time data of environmental parameters of temperature, humidity, and $\mathrm{CO}_{2}$ concentration are commonly monitored and captured. While light intensity has been included with the aid of sensors recently. For specific species, some studies made tremendous contributions to the development of the empirical growth model. Furthermore, it is foreseen those emerging techniques, such as Artificial Intelligence (AI), big data analysis, and computer vision ${ }^{[41-43]}$, will be applied to the area of environmental control in mushroom factories in the near future. 
Table 1 Overview of studies on environmental monitoring and controlling

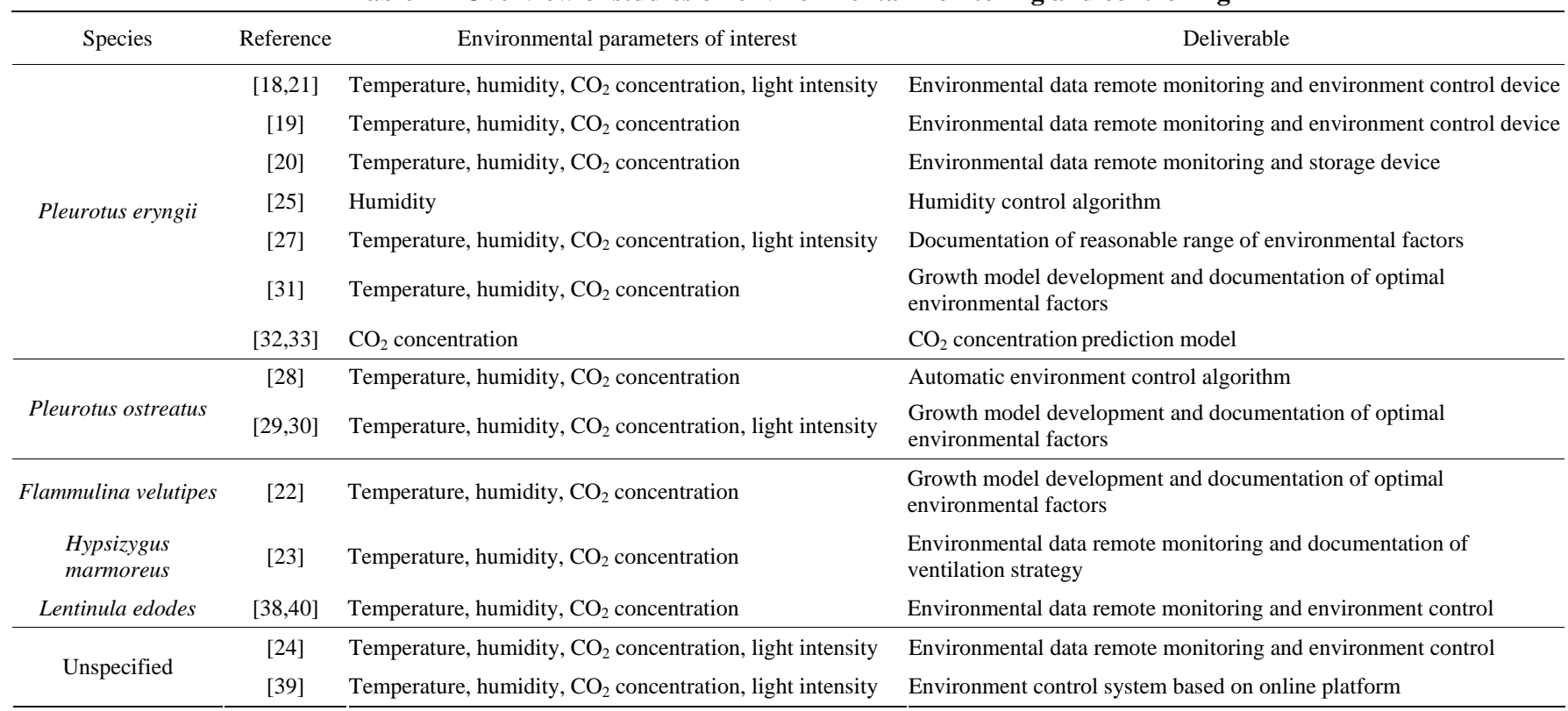

\section{Computer simulation of indoor airflow}

Airflow in controlled-environment facilities plays a crucial role, because all the environmental factors, except for light, are transmitted through the air. Thereby, the uniformity of indoor conditions is highly dependent on internal air circulation. However, airflow is invisible and difficult to track with experimental approaches. Thus, mathematical modelling methodology is usually employed to address airflow related problems.

Computational Fluid Dynamics (CFD) is a sophisticated computer modelling technique widely used in engineering field ${ }^{[44-46]}$. The physical model of CFD is based on two governing equations, Navier-Stokes Equations and Bernoulli's Principle ${ }^{[44]}$. The turbulence model usually plays a critical role in the simulation process, describing the flow behavior upon actual scenario ${ }^{[47-51]}$. Numerical solutions of physical parameters of interest are solved via the methodology of Finite Element Analysis (FEA) ${ }^{[44,52]}$.

\subsection{Uniformity of indoor environment}

CFD models are commonly employed to simulate indoor airflow to examine the distribution of environmental parameters qualitatively and quantitatively, which facilitates agricultural researchers to evaluate the performance of the indoor environment cost-effectively ${ }^{[2,53-57]}$.

Han et al. ${ }^{[58]}$ from South Korea used CFD model to analyze the indoor temperature distribution in an oyster mushroom factory. The study summarized equations of calculating optimal ventilation rate corresponding to outdoor weather conditions. The simulation results suggested changing the direction of incoming airflow and/or installing small fans onto inlets enhance cooling efficacy in summer with a more uniform temperature distribution.

Jeong et al. $^{[59]}$ conducted a CFD analysis of an oyster mushroom farm to assess indoor air circulation performance in cold weather. According to the simulation results, installing circulation fans enhanced indoor air movement and air circulation, which substantially improved the uniformity of indoor temperature distribution. Additionally, the heating efficacy of heaters was improved by eliminating over-heated areas with the addition of circulation fans.

\subsection{Equipment and energy use}

Research has been conducted to find out the best operation manner of equipment in mushroom factory to obtain uniform grow environment using CFD models ${ }^{[54,60-63]}$. Due to the high accuracy of CFD models, the simulation results are reliable to predict actual airflow and environmental conditions ${ }^{[3,64-67]}$.

Jing and Shen ${ }^{[68]}$ employed a CFD model to simulate airflow and temperature distribution in a king oyster mushroom farm. Their validation results revealed a good agreement between the predicted temperature data and experimental measurement with an approximation error below $7.8 \%$. The investigation carried out by Grant examined airflow in growing tunnels of commercial mushroom production in Ireland ${ }^{[69]}$. The researcher modeled an air duct system to properly deliver conditioned air to the cropping surface at suitable speeds and as uniformly as possible. By simulating airflow in the growing tunnel, various flow configurations of air delivery configuration were tested for both single layer and multi-layered growing tunnel. The CFD simulation result suggested reducing the spacing of duct apertures from $0.8 \mathrm{~m}$ to $0.5 \mathrm{~m}$ resulted in an increased air speed at the tunnel floor.

Lee et al. $^{[70]}$ employed CFD model to simulate the indoor climate of an oyster mushroom cultivation house. The study revealed large variations in the distribution of air velocity, temperature, and humidity when all the environmental control equipment were operated simultaneously. Researchers investigated three scenarios of equipment operation and the corresponding indoor airflow patterns (Figure 2). The uniformity of indoor environment was improved when only a cooler and an air circulation fan operating, which indicated reducing the overall operating time of all the equipment benefited the uniformity of indoor environment.

To ensure a uniform temperature distribution in mushroom factory, Ryu et al. ${ }^{[71]}$ developed four CFD models to figure out the optimal locations of the fan coil unit and exhaust fan in a commercial mushroom greenhouse. By comparing CFD simulation output, a relatively uniform temperature distribution was obtained when the circulation path of indoor air became longer, indicating a greater distance between the fan coil unit (as the inlet) and the exhaust fan (as the outlet) could improve air circulation and environment uniformity in this case. 


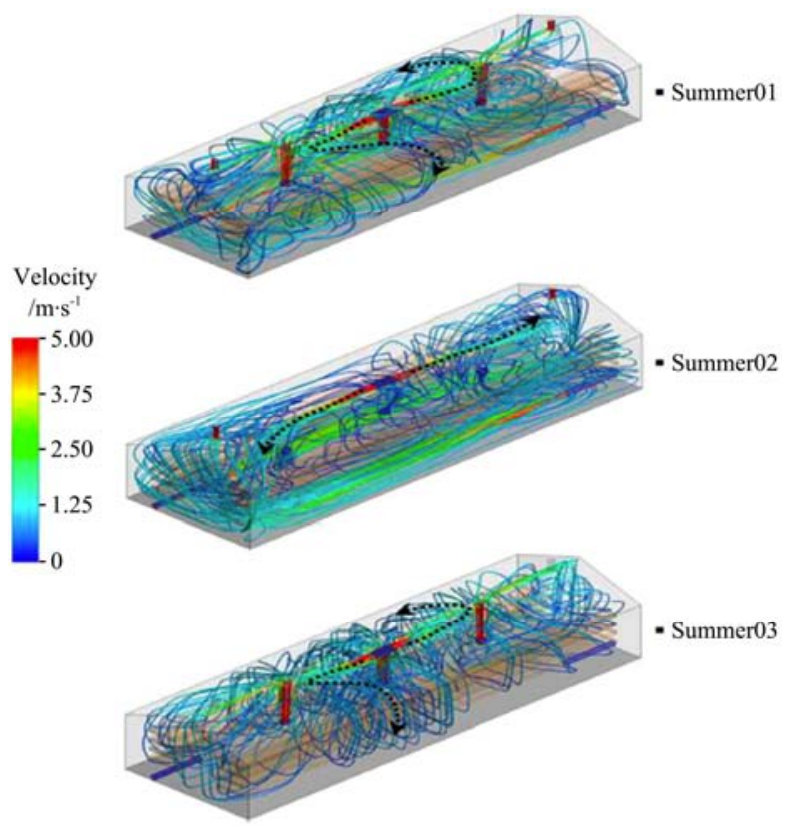

Figure 2 Simulated indoor air streamlines of an oyster mushroom factory at three different scenarios of equipment operation ${ }^{[70]}$

\subsection{Prediction of simulation}

Furthermore, the method of CFD modelling is evolving by integrating data science and information technology. In the era of big data, a few emerging technologies have been integrated into CFD modelling, which aims to make CFD modelling more user-friendly, especially for non-professionals.

Jing and Fang ${ }^{[72]}$ developed an algorithm to predict CFD simulation output by training the Group Method of Data Handling (GMDH) type neural network with previous CFD simulation data. With this method, the running time of CFD simulations was reduced significantly, saving considerable computational resources. The approximation error between the prediction model and the actual CFD simulation result was $4.9 \%$ on average, indicating an excellent accuracy. This study may bring in some inspirations to future studies in the application of machine learning ${ }^{[42,43]}$.

CFD modelling is a powerful tool to address agricultural environmental issues. Unlike the application in other agricultural facilities, so far very few investigations have been performed to evaluate the indoor environment in mushroom facilities (Table 2). However, CFD modelling should be a primary approach to address microclimate issues in modern mushroom facilities as the successful application in other fields of agricultural production.

Table 2 Overview of studies on indoor environment of mushroom facility using CFD modelling

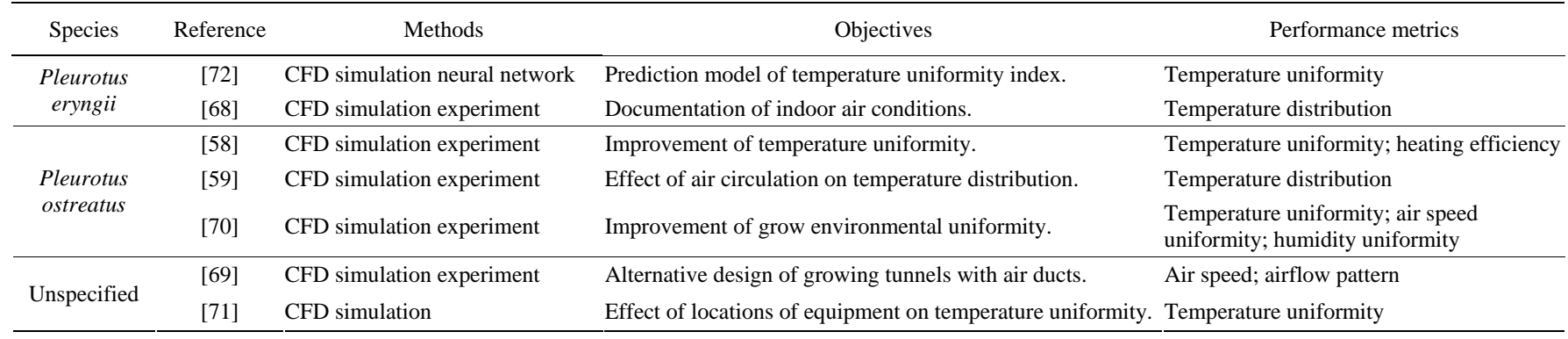

\section{Refinement of cultivation facility}

The current design of mushroom factory was significantly influenced by the design of greenhouse ventilation systems $^{[13,15,73,74]}$, despite some specific criteria between them. First, a well-designed mushroom factory should maintain an optimal indoor environment at various grow phases and accommodate dynamic outdoor conditions by adjusting ventilation rate and/or operating pertinent equipment. The structure of the building should be stable and supportive, particularly satisfying the wind load and snow load. The cultivation room should be provided with sufficient fresh air and internal air circulation to minimize dead zone formation and temperature stratification $^{[4,13,47,75,76]}$. Sometimes, humidification is needed to maintain high relative humidity. In addition, mushrooms are extremely sensitive to $\mathrm{CO}_{2}$ concentration, thus inappropriate indoor gas profile will undermine mushroom quality and profit ${ }^{[77-80]}$.

\subsection{Structure}

Yoon et al. ${ }^{[81]}$ conducted a study comparing two frame types of a king oyster mushroom factory by evaluating the range of individual environmental factors and the relationship associated with yield performance versus energy consumption. The study revealed that for both facilities, the average temperature is lower than set point and the maximum air temperature gap between the upper and lower cultivation locations was about $5^{\circ} \mathrm{C}$, due to a lack of evenly heating and insufficient air circulation. To solve this problem, the researchers upgraded the capacity of the heater and improved internal air circulation.
Similar research was conducted by Suh and Yoon who analyzed the facility structure of a king oyster mushroom factory in South Korea ${ }^{[82]}$, by comparing the arch-roofed type with the sandwich panel type of cultivation facility. Based on the analysis, both types had advantages and disadvantages, while the sandwich panel presented a better performance in structural stability. In addition, Yum et al. ${ }^{[83]}$ employed engineering software to examine the structural stability according to the Allowable Stress Design (ASD) to find out the optimal type of bed column of growing oyster mushrooms.

\subsection{Ventilation}

An investigation on ventilation refinement with regard to a king oyster mushroom factory was carried out by Ahn et al ${ }^{[84]}$. The study evaluated four types of ventilation schemes: parallel-pressure, positive-pressure, negative-pressure, and positive- plus negative-pressure, based on the performance in indoor air circulation, growth rate, as well as the appearance of physiologically abnormal phenotypes. According to their findings, the positive- plus negative-pressure type ventilation scheme presented the highest efficiency of air circulation as the average $\mathrm{CO}_{2}$ concentration was relatively low compared to the other three types. Moreover, mushrooms that grew within this ventilation scheme showed better morphological traits and fewer physiological abnormities, yet with a longer period for harvesting ${ }^{[84]}$.

Another study was conducted to resolve the problem of unevenly distributed temperature and humidity in a multi-layer oyster mushroom cultivation house ${ }^{[85]}$. By installing air circulation fans, the indoor temperature range between different 
locations was $0.2^{\circ} \mathrm{C}-1.3^{\circ} \mathrm{C}$, despite a wide change of outdoor temperature ranging from $13.3^{\circ} \mathrm{C}$ to $18.4^{\circ} \mathrm{C}$. Similarly, though the outdoor humidity changed from $40 \%$ to $100 \%$, the largest spatial difference of indoor relative humidity ranged between $2 \%$ to $7 \%$.

Jeong et al. ${ }^{[86]}$ designed an air circulator to enhance indoor air circulation in an oyster mushroom farm. They constructed a prototype air circulator and measured indoor temperature with three different installation heights of the air circulator. The use of an air circulator was demonstrated to improve the uniformity of temperature distribution.

\subsection{Humidification}

Most edible fungus prefers high humidity at the stage of fruiting body growth ${ }^{[6,22,27,29,31]}$. During some extreme weather, continuous ventilation is needed to cool down the cultivation room by introducing fresh air and/or evaporative cooling ${ }^{[87]}$. However, frequent ventilation usually decreases the indoor humidity due to introducing dry outside air ${ }^{[13]}$. Therefore, humidification is demanded to supply extra moisture to the indoor environment to maintain high humidity.

Kim et al. ${ }^{[88]}$ developed a ventilation model to predict pertinent ventilation rate according to outdoor conditions. Simulation of indoor environment was achieved by using calculated ventilation rate to evaluate the performance of existing ventilation system.
Additionally, humidification was found necessary to maintain the optimal indoor environment for the study mushroom factory.

Islam et al. investigated the effects of different environmental conditions on mushroom morphology, moisture contents of fruiting body, and yields to figure out the most efficient way for indoor cultivation of Pleurotus pulmonarius ${ }^{[89]}$. In this study, mushroom quality was compared within three types of ventilation schemes. The result suggested mushrooms cultivated with both humidification and ventilation had the highest individual weight with outstanding morphological quality, compared to mushrooms that grew under the other two ventilation schemes.

Research on the refinement of mushroom facility design was summarized with a variety of emphases (Table 3). Some studies investigated the structural analysis, focusing on the stability and the spatial utilization rate. Other investigations were conducted to evaluate the performance of ventilation schemes, and the correlation to yields and mushroom quality. In addition, researchers addressed specific indoor environment problems, such as the moisture loss of mushrooms, the need for humidification, and proposed solutions of equipment addition or modifying the ventilation rate. Note, the use of computer modelling will be a significant help to the investigations on facility design. In general, studies in this category are usually practically oriented to resolve specific issues.

Table 3 Overview of studies on mushroom facility refinement

\begin{tabular}{|c|c|c|c|}
\hline Species & Reference & Objectives & Performance metrics \\
\hline \multirow{3}{*}{ Pleurotus eryngii } & [81] & Impact of structure on internal environment and yield. & $\begin{array}{l}\text { Temperature distribution; humidity; } \mathrm{CO}_{2} \text { concentration; illuminance; } \\
\text { product grade }\end{array}$ \\
\hline & {$[82]$} & Structural analysis of tentative facility design. & Snow load; wind load; special characteristics \\
\hline & {$[84]$} & Impact of ventilation on $\mathrm{CO}_{2}$ concentration. & Air speed; $\mathrm{CO}_{2}$ concentration; mushroom morphology \\
\hline \multirow{3}{*}{ Pleurotus ostreatus } & [83] & Structural analysis of facility design. & Snow load; wind load; allowable stress \\
\hline & [85] & Improvement of environment uniformity. & Temperature; relative humidity; $\mathrm{CO}_{2}$ concentration \\
\hline & [86] & Effect of air circulators on environment uniformity. & Temperature \\
\hline Pleurotus pulmonarius & [89] & Effects of humidification and ventilation on yield. & Temperature; humidity; product quality and morphology \\
\hline \multirow{2}{*}{ Unspecified } & [88] & Development of ventilation rate model. & Ventilation rate; temperature; relative humidity; $\mathrm{CO}_{2}$ concentration; air speed \\
\hline & {$[87]$} & Effects of evaporative cooling and continuous ventilation. & Temperature; relative humidity; air change rate \\
\hline
\end{tabular}

\section{Conclusions}

This overview summarized current research progress in three categories with regards to the indoor environment of mushroom facilities. Those studies provided valuable evidence in propelling the evolution of modern mushroom farming. Compared to other types of agricultural production facilities, the increment of the number of mushroom factories is phenomenal, particularly in China. However, more investigations are in great demand to address issues encountered during the transition to modern mushroom farming. Here are some representative problems that need to be addressed:

1) There is a lack of guidelines in the design of mushroom factories, in terms of pertinent ventilation schemes and structural configurations, which left growers in a grey area that totally depends on their practical experiences. Hence, more thorough investigations are needed in facility design combining computer modelling and experimental measurement to establish standardized design criteria that can be documented for certain species cultivation.

2) Practical application of big data analysis and computer vision technologies in mushroom farming management. Current monitor and control algorithms merely integrated acquisition, data transmission, and processing of real-time environmental parameters However, the resulting massive database hasn't been fully utilized and can be trained to create more precise growth models and environment control strategies via methods such as data mining and deep learning. In addition to capturing environmental parameters, cutting-edge computer vision techniques can be employed to detect morphological abnormity and implement grow condition checking via phenotyping. These applications have already been found in other agricultural production, thus should be considered in the scope of next level "Smart Mushroom Farming”.

3) Improving the energy-use efficiency of mushroom facilities. A more sustainable energy plan should be brought out for future mushroom factories. Due to the continuous production mode, the energy consumed by mushroom factories is huge. Thereby, optimization of facility design, for instance, using economizer based on local climatic features to reduce the operation of air conditioning equipment might be a potential solution. Besides, a more accurate mushroom growth model would help the calculation of heating and cooling load to select appropriate equipment without oversizing. Additionally, the use of clean energy such as solar and biofuel may also be worth investigating.

As a summary, previous studies on the indoor environment of modern mushroom farming were overviewed with some insights 
with regards to existing issues. This article is expected to provide references for modern mushroom farming in controlled-environment facilities and inspiration for future studies.

\section{Acknowledgements}

This study was financially supported by the Key Laboratory of Storage of Agricultural Products, Ministry of Agriculture and Rural Affairs (Grant No. Kf2021009 and Kf2021005), Key Research and Development Plan Project of Hebei Province (Grant No. 21326315D), Tianjin “131” Innovative Talent Team (Grant No. 20180337), and Natural Science Foundation of Tianjin City (Grant No. 19JCYBJC29400). The authors acknowledge Tianjin Technology of Mushroom Engineering Center for the support of information and references. The authors also acknowledge the commercial mushroom growers in Tianjin as collaborators in this study.

\section{[References]}

[1] Royse D J. A global perspective on the high five: Agaricus, Pleurotus, Lentinula, Auricularia \& Flammulina. In: International Conference on Mushroom Biology and Mushroom Products, 2014; pp.2010-2015.

[2] Zhang Y, Kacira M, An L L. A CFD study on improving air flow uniformity in indoor plant factory system. Biosystems Engineering, 2016; 147: 193-205.

[3] Wu C R, Cheng R F, Fang H, Yang Q C, Zhang C. Simulation and optimization of air tube ventilation in plant factory based on CFD. Journal of China Agricultural University, 2021; 26(1): 78-87. (in Chinese)

[4] Moon S-M, Kwon S-Y, Lim J-H. Improvement of energy efficiency of plants factory by arranging air circulation fan and air flow control based on CFD. Journal of Internet Computing and Services, 2015; 16(1): 57-65. (in Korean)

[5] Li C T, Tan Q, Bian Y B, Xie B G, Liu Z Q, Li Y. The status and prospection of edible mushroom industry in China. Journal Fungal Research, 2019; 17(1): 1-10. (in Chinese)

[6] Sakamoto Y. Influences of environmental factors on fruiting body induction, development and maturation in mushroom-forming fungi. Fungal Biology Reviews, 2018; 32(4): 236-248.

[7] Sánchez C. Cultivation of Pleurotus ostreatus and other edible mushrooms. Applied Microbiology and Biotechnology, 2010; 85(5): 1321-1337.

[8] Zhang R H, Li X J, Fadel J G. Oyster mushroom cultivation with rice and wheat straw. Bioresource Technology, 2002; 82(3): 277-284.

[9] Lay C H, Sung I Y, Kumar G, Chu C Y, Chen C C, Lin C Y. Optimizing biohydrogen production from mushroom cultivation waste using anaerobic mixed cultures. International Journal of Hydrogen Energy, 2012; 37(21): 16473-16478.

[10] Yang D, Liang J, Wang Y, Sun F, Tao H, Xu Q, et al. Tea waste: An effective and economic substrate for oyster mushroom cultivation. J Sci Food Agric, 2016; 96(2): 680-684.

[11] Grimm D, Wösten H A B. Mushroom cultivation in the circular economy. Appl Microbiol Biotechnol, 2018; 102(18): 7795-7803.

[12] Yang W J, Guo F L, Wan Z J. Yield and size of oyster mushroom grown on rice/wheat straw basal substrate supplemented with cotton seed hull. Saudi Journal of Biological Sciences, 2013; 20(4): 333-338.

[13] Kurtzman Jr R H. Ventilation for mushroom cultivation: the importance of the needs of mushrooms and of the gas laws. Micol Apl Int, 2010; 22(2): 63-78.

[14] Donoghue J D, Denison W C. Shiitake cultivation: Gas phase during incubation influences productivity. Mycologia, 1995; 87(2): 239-244.

[15] Takakura T. Research exploring greenhouse environment control over the last 50 years. Int J Agric Biol Eng, 2019; 12(5): 1-7.

[16] Jang K-Y, Jhune C-S, Park J-S, Cho S-M, Weon H-Y, Cheong J-C, et al. Characterization of fruitbody morphology on various environmental conditions in Pleurotus ostreatus. Mycobiology, 2003; 31(3): 145 . doi: 10.4489/MYCO.2003.31.3.145.

[17] Jhune C-S, Yun H-S, Jang K-Y, Kong W-S, Lee K-H, Lee C-J, et al. The effect of temperature on morphological of fruiting body and cultivated characteristics of oyster mushroom. J Mushroom Sci Prod, 2011; 9(4): 155-160. (in Korean)
[18] Zhao L, Bai X P, Tian X, Zhu X J. Application of environmental monitoring system of virtual instrument in the growth of Eryngii. Journal of Agricultural Mechanization Research, 2015; 37(7): 216-220. (in Chinese)

[19] Xie C, Zhu X, Ning X, Xing K. Design of remote monitoring system for eryngii greenhouse environment in Southern Ningxia. In: IEEE International Symposium on Industrial Electronics, Taipei: IEEE2013; pp.1-5. doi: 10.1109/ISIE.2013.6563599.

[20] Chen G, Zhao C C, Xie C F, Xing K, Zhu X J. Design of remote monitoring system for community-type growth environment of Pleurotus eryngii. Journal Agricultural Mechanization Research, 2015; 37(2): 112-116, 120. (in Chinese)

[21] Zhao L, Zhu X J. The development of remote monitoring system for cultivation environment of Pleurotus eryngii. In: 2015 IEEE International Conference on Information and Automation (ICIA), Lijiang: IEEE, 2015; pp.2643-2648. doi: 10.1109/ICInfA.2015.7279731.

[22] Lee K-W, Jeon J-O, Lee K-J, Kim Y-H, Lee C-J, Jang M-J. Analysis of growth environment of Flammulina velutipes using the smart farm cultivation technology. J Mushrooms, 2019; 17(4): 197-204. (in Korean)

[23] Zhang K, Tian X, Bai N, Zhu X. Design and application of envrionmental monitoring system for hypsizygus marmoreus in the cultivation room. Agricultural Science \& Technology, 2016; 17(12): 2889-2892.

[24] Wang J, He J C, Yang X L, Wang L R. Environmental factors and a control system for edible fungus in greenhouse cultured. Journal of Agricultural Mechanization Research, 2006; 5: 91-95. (in Chinese)

[25] Zhao L, Zhu X J, Bai X P, Tian X Q, Ren Q. Build model for humidity of the Pleurotus eryngii cultivation environment and controller design and Simulation. Journal of Chinese Agricultrual Mechanization, 2016; 37(6): 79-83. (in Chinese)

[26] Kochhar A, Kumar N. Wireless sensor networks for greenhouses: An end-to-end review. Computers Electronics in Agriculture, 2019; 163: 104877. doi: 10.1016/j.compag.2019.104877.

[27] Yoon Y C, Suh W M, Lee H W, Lee C, Lee S, Lee E, et al. Analysis of environment factors in Pleurotus eryngii cultivation house. Journal of Bio-Environment Control, 2003; 12(4): 200-206. (in Korean)

[28] Lee S-H, Yu B-K, Lee C-J, Yun N-K. Development of remote monitoring and control systems in bottle cultivation environments of oyster mushrooms. J Mushrooms, 2017; 15(3): 118-123. (in Korean)

[29] Lee C, Lee S, Lee E, Park H, Kong W. Analysis of growth environment for precision cultivation management of the oyster mushroom 'Suhan'. J Mushrooms, 2018; 16(3): 155-161. (in Korean)

[30] Lee C-J, Park H-S, Lee E, Kong W-S, Yu B-K. Analysis of growth environment by smart farm cultivation of oyster mushroom "Chunchu No 2.”. J Mushroom, 2019; 17(3): 119-125. (in Korean)

[31] Kim K-J, Kim D-M, An H-S, Choi J-K, Kim S-G. Analysis of the growth environment and fruiting body quality of Pleurotus eryngii cultivated by Smart Farming. J Mushrooms, 2019; 17(4): 211-217. (in Korean)

[32] Tian X Q, Zhu X J. Loop control stategies of $\mathrm{CO}_{2}$ concentration based on BPNN for Pleurotus eryngii in a factory farm. Edible Fungi of China, 2016; 35(2): 46-49. (in Chinese)

[33] Tian X Q, Zhang K, Bai N P, Zhu X J. Online prediction control model of $\mathrm{CO}_{2}$ concentration for Pleurotus eryngii in the sporocarp period based on Matlab and LabVIEW. Applied Mechanics and Materials, 2017; 868: 45-50.

[34] Talavera J M, Tobón L E, Gómez J A, Culman M A, Aranda J M, Parra D $\mathrm{T}$, et al. Review of IoT applications in agro-industrial and environmental fields. Computers and Electronics in Agriculture, 2017; 142(PartA): 283-297.

[35] Zervopoulos A, Tsipis A, Alvanou A G, Bezas K, Papamichail A, Vergis S, et al. Wireless sensor network synchronization for precision agriculture applications. Agriculture, 2020; 10(3): 89. doi: 10.3390/ agriculture 10030089.

[36] Lopez-Iturri P, Celaya-Echarri M, Azpilicueta L, Aguirre E, Astrain J J, Villadangos J, et al. Integration of autonomous wireless sensor networks in academic school gardens. Proceedings, 2018; 18(11): 108. doi: 10.3390/ecsa-4-04899.

[37] Ganchev I, Ji Z, O’Droma M. Designing a low-cost data transfer unit for use in IoT applications. In: 2016 8th International Congress on Ultra Modern Telecommunications and Control Systems and Workshops (ICUMT), Lisbon: IEEE, 2016; pp.85-88. doi: 10.1109/ICUMT.2016. 7765337.

[38] Kassim M R M, Mat I, Yusoff I M. Applications of internet of things in 
mushroom farm management. In: 2019 13th International Conference on Sensing Technology (ICST), Sydney: IEEE, 2019; pp.1-6. doi: 10.1109/ ICST46873.2019.9047702.

[39] Marzuki A, Ying S Y. Environmental monitoring and controlling system for mushroom farm with online interface. Int J Comput Sci Inf Technol, 2017; 9(4): 17-28.

[40] Kassim M R M, Harun A N, Yusoff I M, Mat I, Kuen C P, Rahmad N. Applications of wireless sensor networks in Shiitake Mushroom cultivation. In: 2017 Eleventh International Conference on Sensing Technology (ICST) 2017; pp.1-6. doi: 10.1109/ICSensT.2017.8304516.

[41] Hu C, Zhu X, Zhou Y. The use of NoSQL in product traceability system construction. In: 2018 5th International Conference on Information Science and Control Engineering (ICISE), Zhengzhou: IEEE, 2018; pp.574-577. doi: 10.1109/ICISCE.2018.00124.

[42] Tongcham P, Supa P, Pornwongthong P, Prasitmeeboon P. Mushroom spawn quality classification with machine learning. Computers and Electronics in Agriculture, 2020; 179: 105865. doi: 10.1016/j.compag. 2020.105865

[43] Rehman T U, Mahmud M S, Chang Y K, Jin J, Shin J. Current and future applications of statistical machine learning algorithms for agricultural machine vision systems. Computers and Electronics in Agriculture, 2019; 156: 585-605.

[44] Cengel Y A, Cimbala J M. Fluid mechanic: Fundamental and applications (Chapter 15). 3rd ed. New York: McGraw-Hil, 2013; pp.880-930.

[45] Norton T, Sun D-W, Grant J, Fallon R, Dodd V. Applications of computational fluid dynamics (CFD) in the modelling and design of ventilation systems in the agricultural industry: A review. Bioresource Technology, 2007; 98(12): 2386-2414.

[46] Lee I B, Bitog J P P, Hong S W, Seo I H, Kwon K S, Bartzanas T, et al. The past, present and future of CFD for agro-environmental applications. Computers and Electronics in Agriculture, 2013; 93: 168-183.

[47] Nielsen P V. Fifty years of CFD for room air distribution. Building and Environment, 2015; 91: 78-90

[48] Peng L, Nielsen P V, Wang X X, Sadrizadeh S, Liu L, Li Y G. Possible user-dependent CFD predictions of transitional flow in building ventilation. Building and Environment, 2016; 99: 130-141.

[49] Sørensen D N, Nielsen P V. Quality control of computational fluid dynamics in indoor environments. Indoor Air, 2003; 13(1): 2-17.

[50] Choi K, Albright L D, Timmons M B. An application of the k-e turbulence model to predict how a rectangular obstacle in a slot-ventilate enclosure affects airflow. Transactions of the ASAE, 1990; 33(1): 274-281.

[51] Rong L, Nielsen P V, Bjerg B, Zhang G Q. Summary of best guidelines and validation of CFD modeling in livestock buildings to ensure prediction quality. Computers and Electronics in Agriculture, 2016; 121: 180-190.

[52] Wilcox D C. Turbulence modeling for CFD. Dcw Industries, Incorporated, 1998; 540p

[53] Seo I H, Lee I B, Moon O K, Kim H T, Hwang H S, Hong S W, et al. Improvement of the ventilation system of a naturally ventilated broiler house in the cold season using computational simulations. Biosystems Engineering, 2009; 104(1): 106-117.

[54] Norton T, Grant J, Fallon R, Sun D W. Optimising the ventilation configuration of naturally ventilated livestock buildings for improved indoor environmental homogeneity. Building and Environment, 2010; 45(4): 983-995.

[55] Delele M A, Schenk A, Ramon H, Nicolaï B M, Verboven P. Evaluation of a chicory root cold store humidification system using computational fluid dynamics. Journal of Food Engineering, 2009; 94(1): 110-121.

[56] Delele M A, Schenk A, Tijskens E, Ramon H, Nicolaï B M, Verboven P. Optimization of the humidification of cold stores by pressurized water atomizers based on a multiscale CFD model. Journal of Food Engineering, 2009; 91(2): 228-239.

[57] Delele M A, Tijskens E, Atalay Y T, Ho Q T, Ramon H, Nicolaï B M, et al. Combined discrete element and CFD modelling of airflow through random stacking of horticultural products in vented boxes. Journal of Food Engineering, 2008; 89(1): 33-41.

[58] Han J H, Kwon H J, Yoon J Y, Kim K, Nam S W, Son J E. Analysis of the thermal environment in a mushroom house using sensible heat balance and 3-D computational fluid dynamics. Biosystems Engineering, 2009; 104(3): 417-424.

[59] Jeong W-G, Lim H-K, Kim T-H. Analysis of air circulation in oyster mushroom farm. J. of Biosystems Eng., 2012; 37(2): 75-81.
[60] Tanaka F, Konishi Y, Kuroki Y, Hamanaka D, Uchino T. The use of CFD to improve the performance of a partially loaded cold store. Journal of Food Process Engineering, 2012; 35(6): 874-880.

[61] Moureh J, Flick D. Airflow characteristics within a slot-ventilated enclosure. International Journal of Heat and Fluid Flow, 2005; 26(1): 12-24.

[62] Moureh J, Letang G, Palvadeau B, Boisson H. Numerical and experimental investigations on the use of mist flow process in refrigerated display cabinets. International Journal of Refrigeration, 2009; 32(2): 203-219.

[63] Moureh J, Tapsoba S, Derens E, Flick D. Air velocity characteristics within vented pallets loaded in a refrigerated vehicle with and without air ducts. International Journal of Refrigeration, 2009; 32(2): 220-234.

[64] Bjerg B, Cascone G, Lee I B, Bartzanas T, Norton T, Hong S W, et al. Modelling of ammonia emissions from naturally ventilated livestock buildings. Part 3: CFD modelling. Biosystems Engineering, 2013; 116(3): 259-275.

[65] Mirade P S, Kondjoyan A, Daudin J D. Three-dimensional CFD calculations for designing large food chillers. Computers and Electronics in Agriculture, 2002; 34(1-3): 67-88.

[66] Moureh J, Tapsoba M, Flick D. Airflow in a slot-ventilated enclosure partially filled with porous boxes: Part I - Measurements and simulations in the clear region. Computers and Fluids, 2009; 38(2): 194-205.

[67] Moureh J, Tapsoba M, Flick D. Airflow in a slot-ventilated enclosure partially filled with porous boxes: Part II - Measurements and simulations within porous boxes. Computers and Fluids, 2009; 38(2): 206-220.

[68] Jing L, Shen M. CFD simulation and verification of flow and temperature fields in mushroom house. Journal of Chinese Agricultural Mechanization, 2016; 37(6): 84-88. (in Chinese)

[69] Grant J. Modelling airflow in Irish mushroom growing tunnels. In: Zazueta F S, Xin J, editors. In: Proceedings of the World Congress of Computers in Agriculture and Natural Resources, Iguacu Falls, Brazil: ASABE, 2013; pp. 484-490. doi: 10.13031/2013.8370.

[70] Lee S-H, Yu B-K, Lee C-J, Lim Y-T. The study on enhanced micro climate of the oyster mushroom cultivation house with multi-layered shelves by using CFD analysis. J Mushrooms, 2017; 15(1): 14-20. (in Korean)

[71] Ryu K-J, Son J-H, Han C-W, Nah K-D. A study on the design of air conditioning system in the mushroom cultivation greenhouse. J Korea Acad Coop Soc, 2017; 18(2): 743-750. (in Korean)

[72] Jing L, Fang Q. Prediction model of CFD temperature uniformity of mushroom house based on neural network. Journal of Chinese Agricultural Mechanization, 2019; 40(6): 71-75. (in Chinese)

[73] Boulard T, Kittas C, Roy J C, Wang S. SE-structures and environment: Convective and ventilation transfers in greenhouses, Part 2: Determination of the distributed greenhouse climate. Biosystems Engineering, 2002; 83(2): 129-147.

[74] Zhu Z, Dong H, Zhou Z, Topper P A, Wheeler E F, Zajaczkowski J S L, et al. The potential for plants to trap emissions from farms with laying hens: 2. Ammonia and dust. Journal of Applied Poultry Research, 2008; 17(3): 398-411.

[75] Lomax K, Beyer D, Rhodes T. Air flow effects on mushroom production. In: Royese D, editor. Mushroom biology and mushroom products. State College, PA, USA: The Pennsylvania State University, 1996; pp.233-240.

[76] Jang M J, Ha T M, Lee Y H, Ju Y C. Growth characteristics of variety of oyster mushroom (Pleurotus ostreatus) as affected by number of air exchanges. Journal of Bio-Environment Control, 2009; 18: 208-214. (in Korean)

[77] Ryu J, Kim M, Cho S, Yun Y, Seo W, Lee H. Optimal CO2 level for cultivation of Pleurotus eryngii. J Mushroom Sci Prod, 2005; 3(3): 95-99. (in Korean)

[78] Pavlík M, Fleischer P, Fleischer P, Pavlík M, Šuleková M. Evaluation of the carbon dioxide production by fungi under different growing conditions. Current Microbiology, 2020; 77(9): 2374-2384.

[79] Pavlík M, Fleischer P, Fleischer P, Pavlík M, Šuleková M, Sakamoto Y. Influences of environmental factors on fruiting body induction, development and maturation in mushroom-forming fungi. Current Microbiology, 2020; 32(9): 2374-2384.

[80] Won S Y, Jang M J, Ju Y C, Lee Y B. Optimum $\mathrm{CO}_{2}$ concentration for fruit-body formation and yield of Pleurotus ferulae mushroom in the growing facilitiy for bottle cultivation. Journal of Bio-Environment Control, 2010; 19(2): 77-81. (in Korean)

[81] Yoon Y C, Suh W M, Lee I B. Analysis of environment factors in 
Pleurotus eryngii cultivation house of permanet frame type structure. Journal of Bio-Environment Control, 2006; 15(2): 125-137. (in Korean)

[82] Suh W-M, Yoon Y-C. Data Analysis for structural design of Pleurotus eryngii cultivation facilities. J Korean Soc Agric Eng, 2005; 47(3): 29-37. (in Korean)

[83] Yum S-H, Yun N-K, Kim C-S. Evaluation of structural stability of a simple-typed cultivation facility for growing Pleurotus ostreatus. Journal of Bio-Environment Control, 2008; 17(3): 181-187. (in Korean)

[84] Ahn M-J, Lee S-W, Lee C-H. Effects of various ventilation systems on the carbon dioxide concentration and fruiting body formation of king oyster mushroom (Pleurotus eryngii) grown in culture bottles. Journal of Life Science, 2007; 17(1): 82-90. (in Korean)

[85] Lee S, Yu B, Kim H, Yun N, Jung J. Technology for improving the uniformity of the environment in the oyster mushroom cultivation house by using multi-layered shelves. Prot Hortic Plant Fact, 2015; 24(2): 128-133.

\section{(in Korean)}

[86] Jeong W G, Lim H K, Kim T H. Study on the effect of air circulator on temperature distribution in an oyster mushroom farm. Journal of Biosystems Engineering, 2013; 38(2): 81-86.

[87] Thepa S, Kirtikara K, Hirunlabh J, Khedari J. Improving indoor conditions of a Thai-style mushroom house by means of an evaporative cooler and continuous ventilation. Renewable Energy, 1999; 17(3): 359-369.

[88] Kim K S, Han J H, Kim M K, Nam S W. Development of a ventilation model for mushroom house using adiabatic panel. Journal of the Korean Society of Agricultural Engineers, 2004; 46: 35-44.

[89] Islam T, Zakaria Z, Hamidin N, Bin Mohd Ishak M A. Indoor cultivation model of humidifying and ventilation systems for grey oyster mushroom (Pleurotus pulmonarius). Indian Journal of Science and Technology, 2017; 10(41): 1-12. 